\title{
Leptospirosis in a subsistence farming community in Brazil
}

\author{
Hênio G. Lacerda ${ }^{a}$, Gloria R. Monteiroa ${ }^{a}$ Carlos C.G. Oliveira ${ }^{a}$, Fernando B. Suassuna ${ }^{a}$, \\ Jose W. Queiroz ${ }^{a}$, James D.A. Barbosa ${ }^{a}$, Daniella R. Martins ${ }^{a}$, Mitemayer G. Reis ${ }^{b}$, Albert I. \\ Kob,c, and Selma M.B. Jeronimo ${ }^{a}{ }^{*}$

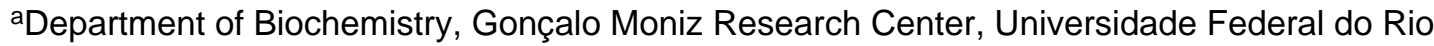 \\ Grande do Norte, CP 1624, Natal, RN, 59078-970, Brazil \\ ${ }^{\mathrm{b}}$ Division of International Medicine and Infectious Diseases, Oswaldo Cruz Foundation/Brazilian \\ Ministry of Health, Salvador, Brazil \\ 'Weil Medical College of Cornell University, New York, USA
}

\section{Summary}

Leptospirosis has been reported in rural areas of Brazil. However, there is limited information about the exposure risk or the risk of Leptospira infection for rural-based populations. A crosssectional study was carried out in order to determine the prevalence and risk factors for prior Leptospira infection in a rural subsistence farming region of the state of Rio Grande do Norte, an area in which outbreaks of leptospirosis have occurred. Among 290 individuals enrolled, 44 $(15.2 \%)$ had anti-Leptospira IgM antibodies as determined by IgM ELISA. Infection tended to occur with activities related to the rice fields $(P=0.08)$. Our findings indicate that Leptospira infection occurs even in years of low rainfall, and may have an important impact among poor rural-based subsistence farmers in Brazil. Additional studies are needed to characterize the mode of transmission in this region.

\section{Keywords}

Leptospirosis; Disease outbreaks; Surveillance; Prevalence; Rural population; Brazil

\section{Introduction}

Leptospirosis is a disease with ubiquitous distribution and is highly endemic in countries with tropical climates. Leptospirosis has emerged to become a public health threat in Latin America (Everard and Everard, 1993; Ko et al., 1999; Martinez et al., 1993; McBride et al., 2005). There is limited information on disease burden, and it is most pronounced in rural regions of developing countries, among subsistence farmers and livestock herders (Everard

\footnotetext{
(C) 2008 Royal Society of Tropical Medicine and Hygiene. Published by Elsevier Ltd. All rights reserved "Corresponding author. Tel./fax: +55 843215 3428. smbj@cb.ufrn.br (S.M.B. Jeronimo)..

Publisher's Disclaimer: This is a PDF file of an unedited manuscript that has been accepted for publication. As a service to our customers we are providing this early version of the manuscript. The manuscript will undergo copyediting, typesetting, and review of the resulting proof before it is published in its final citable form. Please note that during the production process errors may be discovered which could affect the content, and all legal disclaimers that apply to the journal pertain.

Authors' contributions: JWQ, MGR, AIK and SMBJ designed the study; HGL performed the field work, enrolled subjects and wrote the first draft of the manuscript; GRM, CCGO, JDAB, DRM, AIK and SMBJ assisted with the field work; FBS assisted with patient enrolment and ascertainment of the diagnosis; GRM performed the laboratory studies; JWQ did the statistical analysis; CCGO, JDAB, DRM, MGR, AIK and SMBJ revised the manuscript. All authors read and approved final manuscript. SMBJ is guarantor of the paper. 
et al., 1992; Kuriakose et al., 1997; Martinez et al., 1993). In China, there are more than 500 000 cases annually, the majority of which are reported from rural areas of the country. The example of the emergence of leptospirosis in rural Thailand during the 1990s demonstrated the potential magnitude of this problem: a nationwide outbreak occurred in the late 1990s and in 2000 and was responsible for more than 10000 reported cases (Phraisuwan et al., 2002).

Outside of outbreak situations, the overall burden of rural leptospirosis is likely to be significantly under-recognized (Everard et al., 1992; Perrocheau and Perolat, 1997; Russell et al., 2003). In areas where rural leptospirosis has been studied systematically, a large proportion of the population has been found to have had previous exposure to Leptospira (Ashford et al., 2000; Johnson et al., 2004; Kuriakose et al., 1997). Studies performed in Peru found that the prevalence of prior Leptospira infection was $16.5 \%$ among subsistence farming communities (Johnson et al., 2004).

Leptospirosis epidemics have been reported in Brazil since the 1960s, mostly from urban centres (Azevedo and Corrêa, 1968; Caldas and Sampaio, 1977; Caldas et al., 1979). However, large rural outbreaks were first identified in the 1980s, occurring in rice plantation regions of Northeast Brazil (Lima et al., 1996; Secretaria Estadual da Saúde do Rio Grande do Norte, 1997; Suassuna et al., 1986). Recently, a study conducted in the state of Rondonia in Brazil showed that $10 \%$ of the population had serological evidence for a prior infection by Leptospira (Aguiar et al., 2007). Herein, we report findings of surveillance and a seroprevalence survey, which aimed to determine the impact of rural leptospirosis among the subsistence farming population in Rio Grande do Norte, a state in Northeast Brazil.

\section{Materials and methods}

\subsection{Study site and surveillance for leptospirosis}

Rio Grande do Norte is a state located in Northeast Brazil, where outbreaks of leptospirosis were first recognized in the rural semiarid western region in 1985 . The population in this region is composed of subsistence farming communities that grow rice, beans and corn. At the time of the first outbreak in 1985 and afterwards, patients who presented with an acute febrile illness with myalgias and headache were investigated to confirm the diagnosis of leptospirosis. Blood samples were collected and laboratory confirmation of leptospirosis was determined according to protocols of the Brazilian Ministry of Health (Ministério da Saúde, 1995) using the the macroagglutination test (MAT) (Brandao et al., 1998) performed at the Laboratory of the State Secretary of Health of São Paulo, a reference centre for leptospirosis in Brazil. The standard WHO recommended battery of serovars was used for MAT evaluation (Faine et al., 1999; WHO, 2003).

\subsection{Rainfall data}

Rainfall measurements $\left(\mathrm{mm}^{3}\right)$ for the period between 1985 and 1999 were obtained from the registries of Emparn (see http://www.emparn.rn.gov.br/ [accessed May 2008]). Although the annual rainfall can reach up to $1600 \mathrm{~mm}$, the rainfall season is short and occurs mainly between January and June, while rainfall is minimal in the remaining period. Droughts occur in a cyclic pattern, with time spans of 3-5 years.

\subsection{Seroprevalence study}

2.3.1. Study population-The study was conducted in the rural area of São Miguel in 2001. The rural population of the municipality (population, 20124 ) has 1825 houses and a population of 8469 inhabitants (see http://www.ibge.gov.br [accessed May 2008]).

Agricultural activities are the main source of income. Six among the thirteen census zones 
that comprise rural São Miguel were randomly selected as the study site. Each census zone consisted of three to six villages. Two villages were randomly selected for the census zone with less than and more than, respectively, 500 people. Households were assigned a number within selected villages. A random number generator was used to select $10 \%$ of the households within villages for inclusion in the study. All residents of selected households were eligible for the study and were enrolled using written informed consent procedures approved by the University of Rio Grande do Norte Ethical Committee (CEPUFRN 39/01), Oswaldo Cruz Foundation and by the Brazilian National Ethical Committee (CONEP number 4582).

2.3.2. Data collection-A standardized questionnaire was administered during interviews to obtain information on: demographic data (age, gender, time at present residence and work in the rice fields); agricultural activities such as harvesting rice, grass, corn, manioc, beans and sugarcane, and raising or caring for various types of cattle; the use of protective footwear; exposure to water sources during leisure activities; the presence of reservoirs in the home and on plantations; and a past history of leptospirosis.

2.3.3. Anti-Leptospira antibodies-Blood samples were tested for the presence of antiLeptospira IgM antibodies by an ELISA (Bio-Manguinhos, Rio de Janeiro, Brazil) (McBride et al., 2007). This assay is used by the Brazilian Ministry of Health for laboratory confirmation of leptospirosis and has a sensitivity of $100 \%$ in identifying antibodies during the convalescent phase of the illness among cases confirmed by the standard MAT. The cutoff value corresponded to the absorbance value of the 98th percentile of blood bank donors from Brazil. The prevalence of prior Leptospira infection was determined based on cases having a positive IgM reaction as determined by the IgM ELISA. Like other anti-whole Leptospira IgM antibody-based detection assays, the ELISA detects antibodies against carbohydrate moieties, which may persist for up to 5 years after infection (Cumberland et al., 2001; Lupidi et al., 1991). In addition, a random number generator was used to select a sample of sera from study subjects, which were subsequently evaluated in the MAT, as previously described (Ko et al., 1999). A MAT greater than 100 was used as evidence for a prior Leptospira infection.

\subsection{Statistical analysis}

The data were stored in EpiInfo 6.04 software (CDC, Atlanta, GA, USA) database. A case of prior Leptospira infection was defined as having a positive IgM ELISA reaction. Univariate analysis was performed to evaluate risk factors for acquiring a prior Leptospira infection. The $\chi^{2}$ and Fisher's exact tests were used to determine significance between proportions. ANOVA and Wilcoxon's tests were used to assess significant differences for continuous data. The influence of rainfall on number of cases of leptospirosis was analysed in a linear regression model that included the year, the yearly rainfall value and the number of cases notified. The net effect of rainfall was measured by the semi-partial correlation between the last two variables.

\section{Results}

\subsection{Surveillance for leptospirosis outbreaks in Rio Grande do Norte, Brazil}

In the western region of Rio Grande do Norte, rural epidemics of leptospirosis were first identified in 1985. A total of 2180 cases of clinically suspected leptospirosis was reported between 1985 and 2005 (Figure 1). The major clinical findings were fever, headaches, arthralgia, myalgia, cough and dyspnea. None of the subjects were reported to have had complications such as Weil's disease. Of the 250 cases for which serological testing was performed, $50 \%$ were laboratory confirmed. However, the MAT evaluation was performed 
with single serum samples collected only during acute-phase illness, as paired serum samples were not obtained during surveillance. Among the 127 laboratory-confirmed cases, the maximum agglutination titres were directed against L. borgpetersenii serovar Javanica (44.0\%), L. kirschneri serovar Butembo (29.1\%), L. santarosai serovar Brasiliensis (26.0\%), L. interrogans serovar Australis (26.0\%) and L. kirschneri serovar Panama $(24.4 \%)$. The majority of the cases reacted against more than one serotype, with 36.2 and $22.7 \%$, respectively, reacting against two or more serovars.

\subsection{Influence of rainfall}

The epidemics of leptospirosis occurred during years of increased annual rainfall. The highest number of reported cases occurred in 1985, 1986 and 1995, which corresponded to the years with the highest rainfall index. A positive association was found between annual case numbers and year $(P=0.059)$ and rainfall $(P<0.001)$ and the interaction summary term for year and rainfall $(P<0.001)$. The semipartial correlation between rainfall and cases was $0.9691(P<0.001)$, confirming the influence of increased rainfall with increased case numbers of leptospirosis.

\subsection{Leptospiroses seroprevalence study}

Of 320 eligible subjects, $290(91 \%)$ individuals were enrolled into the study from 68 residences located within 15 villages of the rural region of São Miguel. Thirty subjects declined participation in the study. Males constituted $51.7 \%(n=150)$ and females were $48.3 \%(n=140)$. The average age was 28.3 years $( \pm 19.3$, SD), ranging from 5 to 84 years. The per capita household monthly income was less than US $\$ 300.00$ per month for $96.6 \%$ ( $n$ $=280$ ) of the population. Among subjects, $82.7 \%$ were engaged directly in subsistence farming, such as agriculture and animal husbandry.

Of the 290 enrolled subjects, 44 people (15.2\%) had evidence of prior Leptospira infection, as determined by the presence of anti-Leptospira IgM antibodies in the IgM ELISA. MAT evaluation was also done for a randomly selected sample of 61 subjects. Of this sample, 12 $(19.7 \%)$ individuals had a positive agglutination titre. The highest agglutination titres were directed against L. kirschneri serovar Cynopteri (2), L. interrogans serovar Djasiman (2), L. borgpetersenii serovar Tarassovi (2), L. interrogans serovar Australis (2), two or more serovars (2), L. borgpetersenii serovar Javanica (1) and L. noguchii serovar Louisiana (1).

As shown in Table 1, the mean age was not significantly different between seropositive and negative subjects. No association was observed with gender $(P=0.56)$ or time of residence in the household. Prior Leptospira infection was not associated with the planting of rice or other crops, the growing of sugar cane, and care of livestock or milking goats or cows. Of the 240 people who engaged in farming, 237 (98.8\%) did not use protective clothing or footwear during work-related activities. In children and adolescents under the age of 15 ( $n=$ $66), 63.6 \%$ of those who played in waters near the rice plantations had a prior infection $(P=$ $0.08)$. The majority of subjects $(85.7 \%)$ reported sighting domestic rats in their household environments. Among 250 subjects who engaged in agricultural work, 91 (36.4\%) reported sighting 'red' rats (rato vermelho) in their working environment. Subjects did not report sighting other types of wild or domestic rats in this setting. However, significant associations were not found between serologic evidence for prior Leptospira infection and the presence of rats in the household or workplace environments or with the presence of $\operatorname{dogs}(P=0.83)$ or cattle $(P=0.33)$ in the household area. 


\section{Discussion}

Leptospirosis continues to be an important health problem in Brazil (Ko et al., 1999). As this study found, leptospirosis is a public health concern in Rio Grande do Norte, principally for subjects who are directly engaged in subsistence farming. There was a high correlation between case numbers and rainfall index. Furthermore, the seroprevalence study, which was performed 7 years after the last outbreak, found that $15 \%$ of the rural-based study population had evidence for a past Leptospira infection, suggesting that there may have been ongoing transmission even in the absence of an identifiable epidemic. The prevalence of prior Leptospira infection may have been underestimated, as the presence of IgM antibodies were used as marker of prior infection and these antibodies decrease significantly over a 5 year period (Cumberland et al., 2001; Lupidi et al., 1991) In addition, the seroprevalence survey was conducted following a period of successive drought years with significantly low rainfall indices, indicating Leptospira transmission during these dry years. In this way, the burden of Leptospira infection during periods of normal or high rainfall may be higher than estimated in this survey. Nevertheless, the burden of leptospirosis in this site in Northeast Brazil, as indicated by the seroprevalence survey, appears similar to that reported by Aguiar and colleagues in a rural region in West Brazil (Aguiar et al., 2007).

Although epidemics occurred exclusively in rice-cultivating regions of Northeast Brazil (Lima et al., 1996; Suassuna et al., 1986), as in this study site, we did not identify specific work-related risk factors. These findings suggest that exposure to Leptospira may be ubiquitous. In the study community there was a large number of livestock and domestic and wild rodent animal species that could have served as reservoirs for transmission. We did not identify exposures to specific reservoirs that were associated with the risk for prior Leptospira infection. Of note, rice fields were infested with Oligoryzomys nigripes (I. Duarte, unpublished data), the 'red rat', which may be a potential carrier of pathogenic Leptospira. However, other wild and domestic rats may potentially serve as reservoirs that were not reported by study subjects.

We did not identify the aetiologic agent or animal reservoirs for transmission at the subsistence farming community site. In the MAT evaluation of a sample of study subjects, highest agglutination titres were directed to a range of reference serovars, suggesting that several agents may be circulating in this endemic region. However, culture isolation studies need to be performed, as serological approaches may not adequately identify the infecting serogroup (Levett, 2003); alternatively, transmission may have been due to a predominant serovar that belongs to a serogroup that is not represented in the MAT reference panel and that has not been previously identified. Identification of effective control measures will require a systematic investigation of animal reservoirs, as has been done in other rural settings where leptospirosis is endemic (Bunnell et al., 2000; Hartskeerl and Terpstra, 1996).

In contrast to findings of other studies, male gender was not found to be a risk factor for prior Leptospira infection in the study community. In Caledonia, Perrocheau and Perolat (1997) reported that epidemics occurred in rainy months, primarily among male farmers. In another study conducted in North Brazil, males were more often seropositive (Aguiar et al., 2007); however, in our study at the Sao Miguel site, males and females appeared to have similar risks of being exposed to Leptospira. Furthermore, we found that children had similar prevalence rates to those of adults. While adults may be exposed through farming work, children may be exposed to Leptospira in water ponds near the rice fields, when playing and bathing. Although the association was not significant, we found a trend for higher seroprevalence among children who played in water bodies bordering rice plantations. Similar findings have been observed in Trinidad and Barbados (Everard et al., 
1989), where exposure depended largely on the children's age group and was associated with the parents' occupation.

Of importance was the reintroduction of dengue virus in Brazil, which occurred during the mid-1980s and reached the state of Rio Grande do Norte in the late 1990s. Leptospirosis has an overlapping clinical presentation with that of dengue; often it is difficult if not impossible to differentiate the two diseases based on clinical findings. In the Americas, there is growing evidence that leptospirosis is frequently misdiagnosed as dengue (Bruce et al., 2005; Flannery et al., 2001b; Ko et al., 1999; Levett et al., 2000). In the study community, outbreaks of suspected dengue have been reported since 2001, as shown in Figure 1. It is conceivable that a proportion of these cases may have been, in fact, due to leptospirosis. Under-reporting of leptospirosis cases due to diagnostic confusion with dengue may be a possible explanation for the relatively high prevalence of prior Leptospira infection observed in this study, which occurred during a period when cases of leptospirosis were not identified. Finally, the diagnostic dilemma created by the re-emergence of dengue in the Americas underscores the importance of implementing laboratory-based surveillance for acute febrile illnesses in the region and extending diagnostic support to neglected rural regions, where transmission of dengue and leptospirosis has become endemic.

Our study had several limitations. We used the whole-Leptospira IgM ELISA to identify individuals with prior Leptospira infection. Although the MAT is the standard assay used to determine seroprevalence, this assay has been increasingly used (Ashford et al., 2000; Flannery et al., 2001a; Sarkar et al., 2002; Tangkanakul et al., 2000). Furthermore, we evaluated a sample of subject sera in the MAT and found that there was high concordance between the results of the IgM ELISA and MAT, indicating that misclassification of prior infection status was a less likely possibility. Our study was limited by the cross-sectional design of the community-based prevalence survey. Risk exposures may have changed from the time that the prior infection occurred. Furthermore, migration in and out of the study community has been an ongoing phenomenon, especially as men move from rural villages to seek work opportunities in the metropolitan areas of Brazil. A prospective study should therefore be conducted to ascertain the infection and disease in order to obtain more reliable estimates on rates and risk associations.

\section{Acknowledgments}

We thank the municipality of Sao Miguel for providing access to the hospital data and providing personnel for identifying areas of risk of Leptospira infection, Wellington Luiz Souza and Sildomar de Carvalho Silva for their assistance with the field studies, and Dr Warren Johnson of Weil Medical College of Cornell University for helpful discussion of this work.

Funding: This work was funded in part by NIH grants (NIAID R01 AI052473 and FIC D43 TW00919) and Conselho Nacional de Desenvolvimento Científico e Tecnológico (CNPq). SMBJ and MGR are CNPq researchers.

Ethical approval: The study protocol was approved by the Institutional Review Boards of the University of Rio Grande do Norte and Oswaldo Cruz Foundation, Brazilian Ministry of Health in Salvador, Bahia, Brazil (CEPUFRN 90-2002).

\section{References}

Aguiar DM, Cavalcante GT, Camargo LMA, Labruna MB, Vasconcellos SA, Souza GO, Gennari SM. Anti-Leptospira spp. and anti-Brucella spp. antibodies in humans from rural area of Monte Negro Municipality, State of Rondonia, Brazilian Western Amazon. Brazil. J. Microbiol. 2007; 38:93-96.

Ashford DA, Kaiser RM, Spiegel RA, Perkins BA, Weyant RS, Bragg SL, Plikaytis B, Jarquin C, De Lose Reyes JO, Amador JJ. Asymptomatic infection and risk factors for leptospirosis in Nicaragua. Am. J. Trop. Med. Hyg. 2000; 63:249-254. [PubMed: 11421372] 
Azevedo E, Corrêa MOA. Considerações em torno da epidemia de leptospirose na cidade de Recife em 1966. Aspectos epidemiológicos. laboratoriais e clínicos. Rev. Inst. Adolfo Lutz. 1968; 28:85111.

Brandao AP, Camargo ED, Da Silva ED, Silva MV, Abrao RV. Macroscopic agglutination test for rapid diagnosis of human leptospirosis. J. Clin. Microbiol. 1998; 36:3138-3142. [PubMed: 9774553]

Bruce MG, Sanders EJ, Leake JA, Zaidel O, Bragg SL, Aye T, Shutt KA, Deseda CC, Rigau-Perez JG, Tappero JW, Perkins BA, Spiegel RA, Ashford DA. Leptospirosis among patients presenting with dengue-like illness in Puerto Rico. Acta Trop. 2005; 96:36-46. [PubMed: 16083836]

Bunnell JE, Hice CL, Watts DM, Montrueil V, Tesh RB, Vinetz JM. Detection of pathogenic Leptospira spp. infections among mammals captured in the Peruvian Amazon basin region. Am. J. Trop. Med. Hyg. 2000; 63:255-258. [PubMed: 11421373]

Caldas EM, Sampaio MB. Alguns aspectos soro-epidemiológicos da leptospirose em Salvador-Bahia. Rev. Méd. Bahia. 1977; 23:90-106.

Caldas EM, Sampaio MB, Costa E, Miranda G. Estudo epidemiológico de surto de leptospirose ocorrido na cidade Salvador, Bahia, em Maio e Junho de 1978. Rev. Inst. Adolfo Lutz. 1979; 39:85-94.

Cumberland P, Everard CO, Wheeler JG, Levett PN. Persistence of anti-leptospiral IgM, IgG and agglutinating antibodies in patients presenting with acute febrile illness in Barbados 1979-1989. Eur. J. Epidemiol. 2001; 17:601-608. [PubMed: 12086073]

Everard JD, Everard COR. Leptospirosis in the Caribbean. Rev. Med. Microbiol. 1993; 4:114-122.

Everard CO, Hayes RJ, Edwards CN. Leptospiral infection in school-children from Trinidad and Barbados. Epidemiol. Infect. 1989; 103:143-156. [PubMed: 2789146]

Everard CO, Bennett S, Edwards CN, Nicholson GD, Hassell TA, Carrington DG, Everard JD. An investigation of some risk factors for severe leptospirosis on Barbados. J. Trop. Med. Hyg. 1992; 95:13-22. [PubMed: 1740814]

Faine, S.; Adler, B.; Bolin, C.; Perolat, P. Leptospira and Leptospirosis. MediSci; Melbourne, Australia: 1999.

Flannery B, Costa D, Carvalho FP, Guerreiro H, Matsunaga J, Da Silva ED, Ferreira AG, Riley LW, Reis MG, Haake DA, Ko AI. Evaluation of recombinant Leptospira antigen-based enzyme-linked immunosorbent assays for the serodiagnosis of leptospirosis. J. Clin. Microbiol. 2001a; 39:33033310. [PubMed: 11526167]

Flannery B, Pereira MM, Velloso LD, Carvalho CD, De Codes LG, Orrico GD, Dourado CM, Riley LW, Reis MG, Ko AI. Referral pattern of leptospirosis cases during a large urban epidemic of dengue. Am. J. Trop. Med. Hyg. 2001b; 65:657-663. [PubMed: 11716133]

Hartskeerl RA, Terpstra WJ. Leptospirosis in wild animals. Vet. Q. 1996; 18(Suppl. 3):S149-S150. [PubMed: 8933702]

Johnson MA, Smith H, Joeph P, Gilman RH, Bautista CT, Campos KJ, Cespedes M, Klatsky P, Vidal C, Terry H, Calderon MM, Coral C, Cabrera L, Parmar PS, Vinetz JM. Environmental exposure and leptospirosis, Peru. Emerg. Infect. Dis. 2004; 10:1016-1022. [PubMed: 15207052]

Ko AI, Galvao RM, Ribeiro Dourado CM, Johnson WD Jr, Riley LW. Urban epidemic of severe leptospirosis in Brazil. Salvador Leptospirosis Study Group. Lancet. 1999; 354:820-825. [PubMed: 10485724]

Kuriakose M, Eapen CK, Paul R. Leptospirosis in Kolenchery, Kerala, India: epidemiology, prevalent local serogroups and serovars and a new serovar. Eur. J. Epidemiol. 1997; 13:691-697. [PubMed: 9324217]

Levett PN. Usefulness of serologic analysis as a predictor of the infecting serovar in patients with severe leptospirosis. Clin. Infect. Dis. 2003; 36:447-452. [PubMed: 12567302]

Levett PN, Branch SL, Edwards CN. Detection of dengue infection in patients investigated for leptospirosis in Barbados. Am. J. Trop. Med. Hyg. 2000; 62:112-114. [PubMed: 10761734]

Lima CCC, Cavalcante RSBP, Souza WF, Morais NB, Gondim MM, Feitosa IS. Leptospirose no Ceara em 1995. Rev. Soc. Bras. Med. Trop. 1996; 29:95.

Lupidi R, Cinco M, Balanzin D, Delprete E, Varaldo PE. Serological follow-up of patients involved in a localized outbreak of leptospirosis. J. Clin. Microbiol. 1991; 29:805-809. [PubMed: 1890181] 
Martinez SR, Cruz de La PR, Lopez AC. Human leptospirosis behavior in Cuba. Rev. Cubana Med. Trop. 1993; 45:32-41. in Spanish. [PubMed: 7800887]

McBride AJ, Athanazio DA, Reis MG, Ko AI. Leptospirosis. Curr. Opin. Infect. Dis. 2005; 18:376386. [PubMed: 16148523]

McBride AJ, Pereira FA, Da Silva ED, de Matos RB, Da Silva ED, Ferreira AG, Reis MG, Ko AI. Evaluation of the EIE-IgM-Leptospirose assay for the serodiagnosis of leptospirosis. Acta Trop. 2007; 102:206-211. [PubMed: 17618860]

Ministério da Saúde. Manual de Leptospirose. Fundação Nacional de Saúde; Brasilia: 1995.

Perrocheau A, Perolat P. Epidemiology of leptospirosis in New Caledonia (South Pacific): a one-year survey. Eur. J. Epidemiol. 1997; 13:161-167. [PubMed: 9084999]

Phraisuwan P, Whitney EA, Tharmaphornpilas P, Guharat S, Thongkamsamut S, Aresagig S, Liangphongphanthu J, Junthima K, Sokampang A, Ashford DA. Leptospirosis: skin wounds and control strategies, Thailand, 1999. Emerg. Infect. Dis. 2002; 8:1455-1459. [PubMed: 12498663]

Russell KL, Montiel Gonzalez MA, Watts DM, Lagos-Figueroa RC, Chauca G, Ore M, Gonzalez JE, Moron C, Tesh RB, Vinetz JM. An outbreak of leptospirosis among Peruvian military recruits. Am. J. Trop. Med. Hyg. 2003; 69:53-57. [PubMed: 12932097]

Sarkar U, Nascimento SF, Barbosa R, Martins R, Nuevo H, Kalafanos I, Grunstein I, Flannery B, Dias J, Riley LW, Reis MG, Ko AI. Population-based case-control investigation of risk factors for leptospirosis during an urban epidemic. Am. J. Trop. Med. Hyg. 2002; 66:605-610. [PubMed: 12201599]

Secretaria Estadual da Saúde do Rio Grande do Norte. Relatório de vigilância Epidemiológica para Leptospirose. Natal, Brasil: 1997.

Suassuna F, Tavares SC, Paiva AS, Oliveira MSM. Surto Epidêmico de Leptospirose em Plantadores de Arroz na Região Oeste do Estado do Rio Grande do Norte de Março a Junho de 1985. Rev. Soc. Bras. Med. Trop. 1986; 19:116.

Tangkanakul W, Tharmaphornpil P, Plikaytis BD, Bragg S, Poonsuksombat D, Choomkasien P, Kingnate D, Ashford DA. Risk factors associated with leptospirosis in northeastern Thailand, 1998. Am. J. Trop. Med. Hyg. 2000; 63:204-208. [PubMed: 11388516]

WHO. Human Leptospirosis: Guidance for Diagnosis, Surveillance and Control. World Health Organization; Geneva: 2003. 


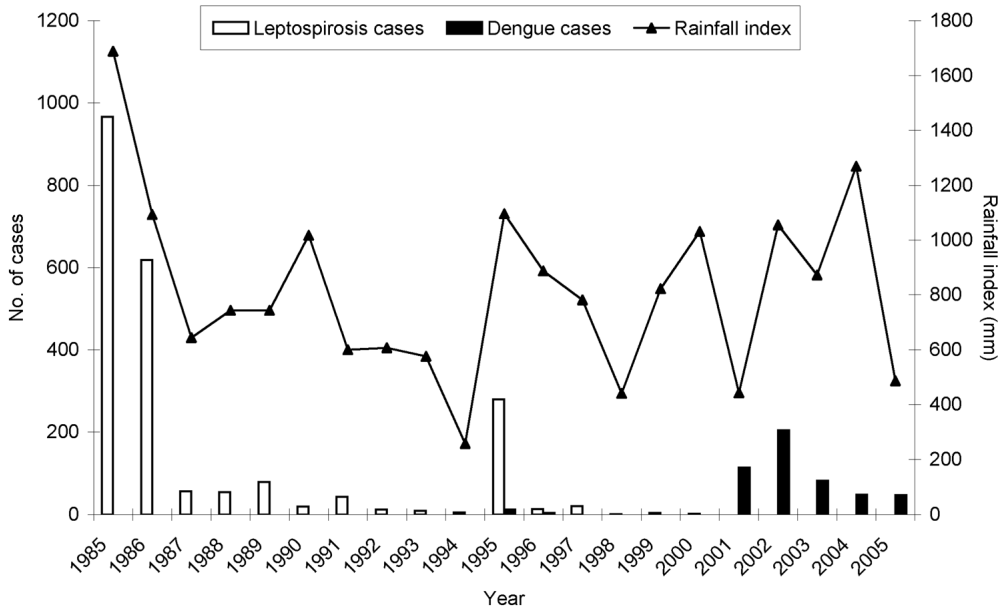

Figure 1.

Confirmed cases of leptospirosis and annual rainfall index in the western region of Rio Grande do Norte, Brazil, 1985-2005. Black and white boxes represent the number of laboratory-confirmed leptospirosis cases and suspected dengue cases ( $y$-axis on left) reported from this subsistence farming region. The line represents the annual accumulated rainfall ( $y$-axis on right). 
